\title{
Correlation between early brain natriuretic peptide level and mortality in cancer patients with septic shock
}

\author{
Yong Yang $^{1,2}$, Jiahua Leng ${ }^{3}$, Renxiong Chen $^{1}$, Hongzhi Wang $^{1}{ }^{\wedge}$, Chunyi Hao $^{2}$ \\ ${ }^{1}$ Department of Critical Care Medicine (ICU), Peking University Cancer Hospital \& Institute, Beijing, China; ${ }^{2}$ Department of Hepato-Pancreato- \\ Biliary Surgery, Peking University Cancer Hospital \& Institute, Beijing, China; ${ }^{3}$ Gastrointestinal Cancer Center, Key laboratory of Carcinogenesis \\ and Translational Research (Ministry of Education/Beijing), Peking University Cancer Hospital \& Institute, Beijing, China \\ Contributions: (I) Conception and design: Y Yang, H Wang; (II) Administrative support: J Leng, C Hao; (III) Provision of study materials or patients: \\ Y Yang, R Chen; (IV) Collection and assembly of data: Y Yang, R Chen; (V) Data analysis and interpretation: Y Yong, H Wang; (VI) Manuscript \\ writing: All authors; (VII) Final approval of manuscript: All authors. \\ Correspondence to: Hongzhi Wang; Chunyi Hao. Peking University Cancer Hospital \& Institute, No. 52 of Fucheng Road, Haidian District, Beijing \\ 100142, China. Email: wanghz58@126.com; haochunyi@bjmu.edu.com.
}

Background: This study aimed to examine the correlation between early brain natriuretic peptide (BNP) levels and mortality in cancer patients with septic shock.

Methods: A retrospective analysis of 159 cancer patients with septic shock admitted to the intensive care unit (ICU) from Dec. 2012 to Dec. 2019 was performed. BNP levels and other variables, including blood lactate (Lac), procalcitonin (PCT), white blood cell (WBC) counts, acute physiology and chronic health status system II scores (APACHE-II scores) were collected within 24 hours after ICU admission. According to 28-day mortality, patients were divided into a death group (60 cases) and a survival group (99 cases). All variables were compared by univariate analysis, and then a multiple logistic regression analysis was performed on the variables that showed significant differences. Receiver operating characteristic curve (ROC curve) analysis was used to evaluate the predictive value of BNP on mortality in cancer patients with septic shock.

Results: BNP, APACHE-II score, Lac, and PCT in the death group were significantly higher than those in the survival group $(\mathrm{P}<0.05)$. Multiple logistic regression analysis of these four variables indicated that BNP, APACHE-II score and Lac were independent risk predictors of mortality in these patients $(\mathrm{P}<0.05)$. The BNP level at $899.6 \mathrm{pg} / \mathrm{mL}$ predicted mortality with a sensitivity of $76.7 \%$ and a specificity of $84.7 \%$. The area under the ROC curve was $0.86 \pm 0.03(\mathrm{P}<0.05)$ for BNP, which was significantly larger than that of the APACHE-II score $(\mathrm{P}<0.05)$ and Lac $(\mathrm{P}<0.05)$.

Conclusions: BNP was an independent risk factor for mortality in cancer patients with septic shock, and had a higher predictive value than the APACHE-II score and Lac.

Keywords: Brain natriuretic peptide (BNP); acute physiology and chronic health status system II score (APACHE-II score); lactate; septic shock

Submitted Nov 06, 2020. Accepted for publication Feb 24, 2021.

doi: 10.21037/apm-20-2212

View this article at: http://dx.doi.org/10.21037/apm-20-2212

^ ORCID: Yong Yang, 0000-0002-1514-722X; Hongzhi Wang, 0000-0002-6238-8384. 


\section{Introduction}

Sepsis is a systemic inflammatory response syndrome caused by infection, which is divided into general sepsis and septic shock according to the 2016 European definition of sepsis 3.0 (1). Relative to patients without malignancy, cancer patients have a nearly 10-fold risk of developing sepsis (2), which is the leading cause of intensive care unit (ICU) admission in such patients (3). In recent cohort studies, the ICU mortality rate ranged from $40 \%$ to $60 \%$ when septic shock and malignancy were present together $(4,5)$.

Brain natriuretic peptide (BNP), an amino acid stored in the ventricular septum membrane, is a classic diagnostic marker of cardiac dysfunction. Following the increase in ventricular wall pressure as a result of cardiac dysfunction, $\mathrm{BNP}$ is secreted into the blood in large quantities, where it exerts diuretic and vasodilating effects (6). Sepsis can increase the pressure of the ventricular wall to abnormal levels, leading to a large quantity of BNP secretion and release into the blood (7). Furthermore, BNP is increased significantly in patients with septic shock, relative to those with general sepsis (8). Septic shock appears to be a strong stimulus of BNP release, and the BNP level has been used successfully to distinguish septic shock from other types of shock $(9,10)$.

This study aimed to clarify the correlation between early BNP levels and mortality in cancer patients with septic shock for early warning and prognostic guidance.

We present the following article in accordance with the STARD reporting checklist (available at http://dx.doi. org/10.21037/apm-20-2212).

\section{Methods}

\section{Participants}

The study was conducted in accordance with the Declaration of Helsinki (as revised in 2013). The study was approved by the Institutional Review Board of Peking University Cancer Hospital (No. 2016KT18). All patients provided written informed consent before inclusion. Clinical data on 159 cancer patients with septic shock admitted to ICU from Dec. 2012 to Dec. 2019 who met the inclusion criteria were collected retrospectively.

Inclusion criteria: patient data were collected according to the 2016 European definition of sepsis 3.0 and septic shock (1). Sepsis refers to the loss of control of the body's inflammatory response to infection leading to lifethreatening organ dysfunction. Organ dysfunction is defined as an acute increase in the Sequential Organ Failure Assessment score (SOFA score $\geq 2$ points) secondary to infection. Septic shock refers to refractory hypotension (patients still need vasopressor drugs to maintain mean arterial pressure $\geq 65 \mathrm{mmHg}$ after adequate fluid resuscitation) and blood lactate (Lac) $\geq 2 \mathrm{mmol} / \mathrm{L}$ (1). After entering the ICU, patients with septic shock were treated by active cluster treatment according to the guidelines of Surviving Sepsis Campaign (SSC) $(11,12)$.

Exclusion criteria: patients with acute coronary syndrome, chronic heart disease (such as severe hypertension, heart valve disease, or arrhythmia), or chronic liver and kidney insufficiency were excluded from the study.

All clinical characteristics (including age, sex, tumor sites, infection sites), Lac, procalcitonin (PCT), white blood cell (WBC), BNP (BNP normal values were less than or equal to $100 \mathrm{pg} / \mathrm{mL}$ ), and acute physiology and chronic health status system II scores (APACHE-II scores) were recorded as early as possible within the first 24 hours of admission to the ICU. The patients were followed up during the ICU stay. All patients were divided into a death group (60 cases) and a survival group (99 cases), according to 28-day mortality. There were no statistically significant differences between the two groups in terms of sex, age, tumor sites and infection sites $(\mathrm{P}>0.05)$ (Table 1).

\section{Statistical analysis}

SPSS Statistics, Version 26.0 (Armonk, NY: IBM Corp.) was used for statistical analysis. Data were analyzed as the mean \pm standard deviation, number, or median. Unpaired $t$-tests and Mann-Whitney $\mathrm{U}$ tests were used to compare continuous variables and those with a skewed distribution, respectively. A $\chi^{2}$ test was used to compare categorical variables. All significantly different variables from univariate analysis were included in multivariate logistic regression analysis so as to select the independent risk factors. Receiver operating characteristic curve (ROC curve) analysis was used to determine the value of all independent risk factors for predicting mortality in cancer patients with septic shock. $\mathrm{P}<0.05$ was considered statistically significant.

\section{Results}

BNP, APACHE-II score, Lac, and PCT in the death group were significantly higher than those in the survival group $(\mathrm{P}<0.05)$, whereas WBC was not significant different between the two groups (Table 2). 
Table 1 General situation of the cancer patients with septic shock

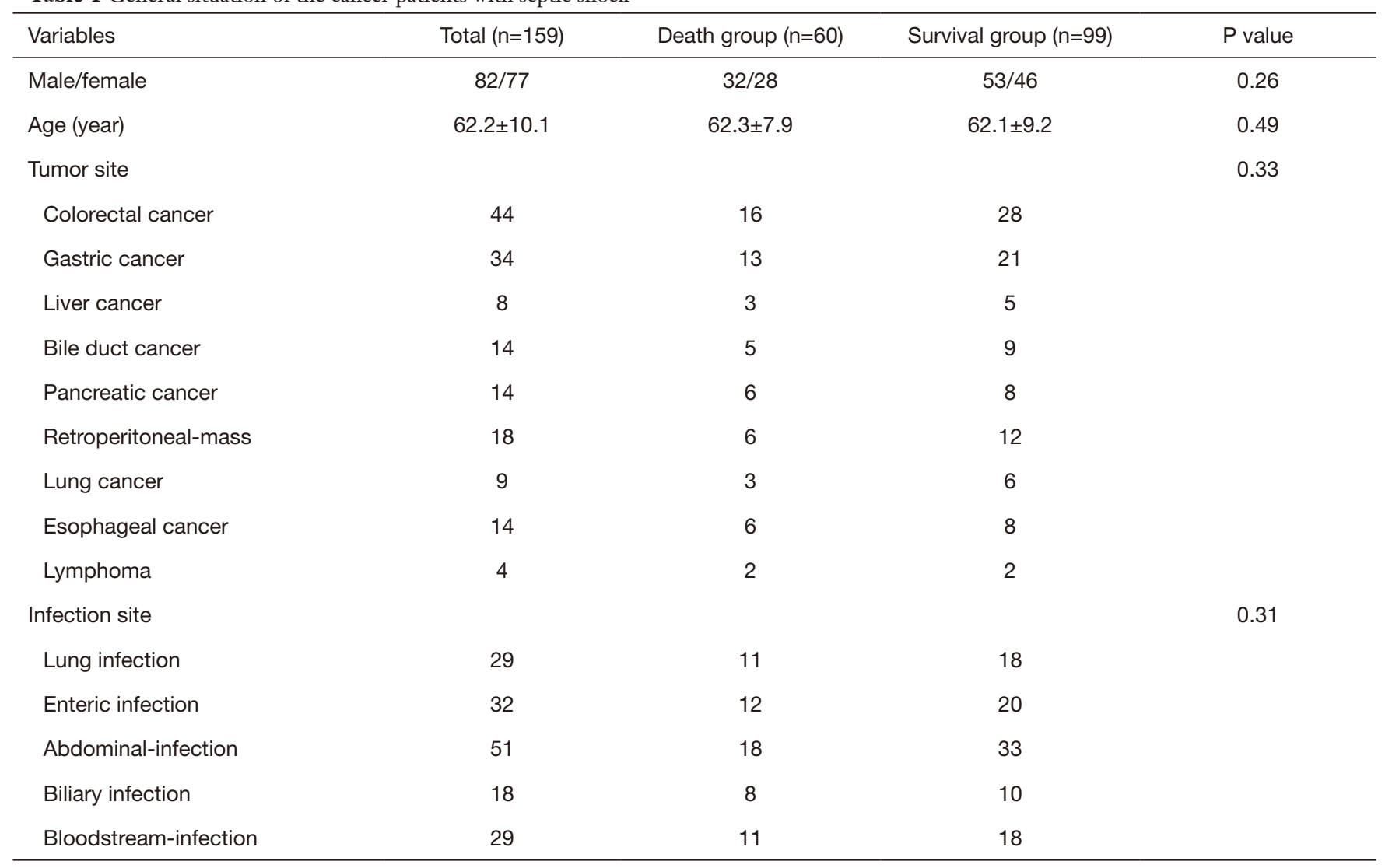

Data were expressed as mean \pm standard deviation, number.

Table 2 Comparison of related variables in the two groups

\begin{tabular}{lccc}
\hline Variables & Death group & Survival group & P value \\
\hline BNP $(\mathrm{pg} / \mathrm{mL})$ & $1,221.17 \pm 1,066.84$ & $819.74 \pm 856.52$ & $0.007^{\star}$ \\
APACHE-II score & $27.59 \pm 10.28$ & $16.62 \pm 6.31$ & $0.001^{\star}$ \\
Lac $(\mathrm{mmol} / \mathrm{L})$ & $6.11 \pm 3.78$ & $3.21 \pm 1.83$ & $0.008^{\star}$ \\
PCT $(\mathrm{ng} / \mathrm{mL})$ & $44.74 \pm 56.79$ & $34.78 \pm 58.90$ & $0.027^{\star}$ \\
WBC $\left(\times 10^{9} / \mathrm{L}\right)$ & $14.28 \pm 8.77$ & $12.57 \pm 9.38$ & 0.387 \\
\hline
\end{tabular}

*, represent $\mathrm{P}<0.05$. Data were expressed as mean \pm standard deviation. BNP, brain natriuretic peptide; APACHE-II score, acute physiology and chronic health status system II score; Lac, lactate; PCT, procalcitonin; WBC, white blood cell.

Multivariate logistic analysis was performed on the variables with significant differences between the two groups, and BNP, APACHE-II score, and Lac were significant, independent predictors of mortality in cancer patients with septic shock $(\mathrm{P}<0.05)$ (Table 3).

ROC curve analysis was used to evaluate the predictive ability of BNP, APACHE-II score, and Lac among cancer patients with septic shock. The BNP level at $899.6 \mathrm{pg} / \mathrm{mL}$ predicted mortality with a sensitivity of $76.7 \%$ and a specificity of $84.7 \%$, APACHE-II score at 17.2 predicted mortality with a sensitivity of $65 \%$ and a specificity of $70.4 \%$, Lac at $3.75 \mathrm{mmol} / \mathrm{L}$ predicted mortality with a sensitivity of $65 \%$ and a specificity of $72.4 \%$. The area under the ROC curve was $0.86 \pm 0.03(\mathrm{P}<0.05)$ for $\mathrm{BNP}$, 
Table 3 Logistic regression analysis in the two groups

\begin{tabular}{|c|c|c|c|c|c|}
\hline Variables & B & Wald & $P$ value & OR & $95 \% \mathrm{Cl}$ \\
\hline APACHE-II score & 0.169 & 15.667 & $0.001^{*}$ & 1.173 & $1.084-1.269$ \\
\hline Lac & 0.263 & 3.904 & $0.028^{*}$ & 1.301 & $1.002-1.689$ \\
\hline
\end{tabular}

*, represent $\mathrm{P}<0.05$. BNP, brain natriuretic peptide; APACHE-II score, acute physiology and chronic health status system II score; Lac, lactate.

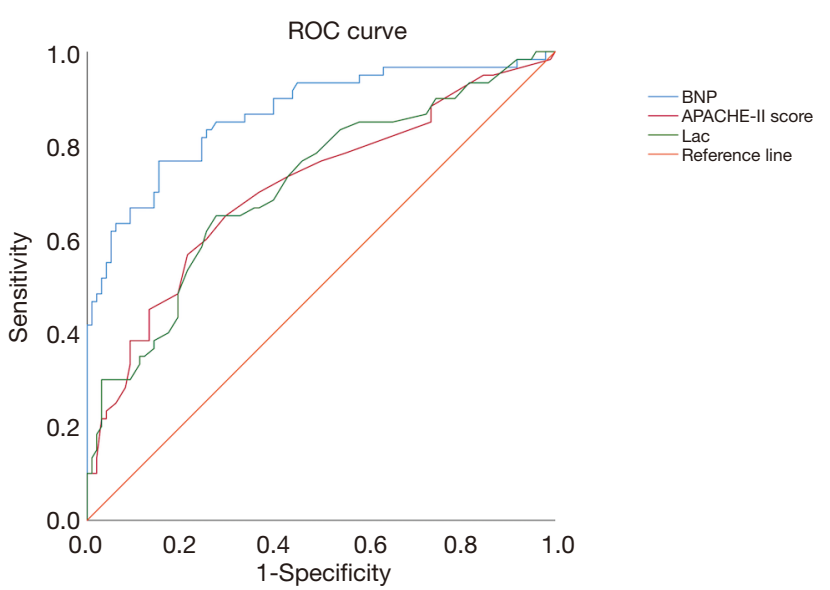

Figure 1 ROC curve for BNP, APACHE-II score and Lac of predicting mortality. The area under the ROC curve of BNP was significantly larger than that of APACHE-II score or Lac $(\mathrm{P}<0.05)$. BNP, brain natriuretic peptide; APACHE-II score, acute physiology and chronic health status system II score; Lac, lactate; ROC curve, receiver operating characteristic curve.

$0.71 \pm 0.04(\mathrm{P}<0.05)$ for APACHE-II score, and $0.72 \pm 0.04$ $(\mathrm{P}<0.05)$ for Lac. The area under the ROC curve of BNP was significantly larger than that of the APACHE-II score $(\mathrm{P}<0.05)$ and Lac $(\mathrm{P}<0.05)$ (Figure 1).

\section{Discussion}

BNP is a member of the natriuretic peptide family. It is mainly produced in the ventricle. Increased ventricular wall tension and increased blood vessel content are the main factors that induce its secretion (6).

In this study, early plasma BNP data were collected retrospectively from 159 cancer patients with septic shock within the first 24 hours after ICU admission over 7 years. The results showed that all cancer patients with septic shock had a significant increase in BNP, which was consistent with the detection of ultra-high concentrations of BNP in patients with septic shock and a significant difference compared with patients who had general sepsis (13). The results also showed that the plasma BNP level was significantly higher in the death group than in the survival group in the first 24 hours after admission to the ICU $(\mathrm{P}<0.05)$. Logistic regression analysis on the two groups of patients indicated that BNP, APACHE-II score, and Lac were independent risk predictors of mortality in cancer patients with septic shock $(\mathrm{P}<0.05)$. The higher the APACHE-II score in the ICU, the more severe the illness and the higher the mortality, which is certain in critically ill patients $(14,15)$. The value of lactic acid for predicting the mortality in patients with septic shock has been confirmed by a large number of relevant studies (16-18). The ROC curve analysis also demonstrated that the early BNP level is a stronger predictor of mortality than the APACHE-II score and Lac $(\mathrm{P}<0.05)$. In view of the above, BNP appears to be a reliable predictor of the outcome in septic shock, and it may serve as a useful laboratory marker to predict mortality in patients with septic shock (19).

A significant increase in BNP in sepsis usually indicates the presence of sepsis-induced myocardial dysfunction (SIMD) (20). With an emphasis on early fluid resuscitation to ensure organ tissue perfusion for patients with septic shock following the 2016 SSC guideline, more attention should be paid to cardiac function and its capacity. SIMD is an important reason for the increase in mortality and lengthening of ICU stay in patients with sepsis (21). Based on the results of this study, we recommend that clinicians perform plasma BNP monitoring on patients with septic shock, and pay more attention to BNP levels equal to or greater than $900 \mathrm{pg} / \mathrm{mL}$ in the first 24 hours after admission to the ICU. When performed by fluid resuscitation, these patients' cardiac function status should be assessed with the help of bedside cardiac ultrasound or pulse-indicating continuous cardiac output monitoring (PICCO) to maintain the balance between fluid volume and cardiac function so as to reduce mortality and improve prognosis (22-24). 


\section{Study limitations}

This study had some limitations. First, in patients admitted to the ICU, the plasma BNP level was limited to active antishock treatment in the first 24 hours. In view of the sepsis treatment guidelines of the SSC, the first 24 hours following ICU admission are the "golden period" for sepsis treatment. The relevant data were reliable. The disadvantage was a lack of continuous monitoring data. Secondly, the patient's cardiac function lacked quantitative parameter evaluation. If the patients' cardiac ultrasound results could be obtained at the same time for comparison with BNP, the correlation between the two of them would become clearer. The above needs to be improved in future research.

\section{Conclusions}

For cancer patients with septic shock, early warning and effective intervention to reduce mortality remain a challenge in the ICU. The early BNP level is of great value for preliminary judgment of cardiac function status and mortality in cancer patients with septic shock.

\section{Acknowledgments}

Thanks Elise' efforts for the English language revision.

Funding: This study was supported by the Capital Health Research and Development of Special Funds (approval No. 2020-1-1021), Beijing Municipal Administration of Hospital's Ascent Plan (approval No. DFL20181104), Beijing Municipal Administration of Hospitals' Youth Programme (approval No. QML20181104), and B. Braun Anaesthesia Science Research Foundation (BBFD-2015-16).

\section{Footnote}

Reporting Checklist: The authors have completed the STARD reporting checklist. Available at http://dx.doi.org/10.21037/ apm-20-2212

Data Sharing Statement: Available at http://dx.doi. org/10.21037/apm-20-2212

Conflicts of Interest: All authors have completed the ICMJE uniform disclosure form (available at http://dx.doi. org/10.21037/apm-20-2212). The authors have no conflicts of interest to declare.
Ethical Statement: The authors are accountable for all aspects of the work in ensuring that questions related to the accuracy or integrity of any part of the work are appropriately investigated and resolved. The study was conducted in accordance with the Declaration of Helsinki (as revised in 2013). The study was approved by the Institutional Review Board of Peking University Cancer Hospital (No. 2016KT18) and informed consent was taken from all the patients or their next of kin.

Open Access Statement: This is an Open Access article distributed in accordance with the Creative Commons Attribution-NonCommercial-NoDerivs 4.0 International License (CC BY-NC-ND 4.0), which permits the noncommercial replication and distribution of the article with the strict proviso that no changes or edits are made and the original work is properly cited (including links to both the formal publication through the relevant DOI and the license). See: https://creativecommons.org/licenses/by-nc-nd/4.0/.

\section{References}

1. Singer M, Deutschman CS, Seymour CW, et al. The third international consensus definitions for sepsis and septic shock (Sepsis-3). JAMA 2016;315:801-10.

2. Danai PA, Moss M, Mannino DM, et al. The epidemiology of sepsis in patients with malignancy. Chest 2006;129:1432-40.

3. Soares M, Caruso P, Silva E, et al. Characteristics and outcomes of patients with cancer requiring admission to intensive care units: a prospective multicenter study. Crit Care Med 2010;38:9-15.

4. Pène F, Percheron S, Lemiale V, et al. Temporal changes in management and outcome of septic shock in patients with malignancies in the intensive care unit. Crit Care Med 2008;36:690-6.

5. Namendys-Silva SA, González-Herrera MO, TexcocanoBecerra J, et al. Clinical characteristics and outcomes of critically ill cancer patients with septic shock. QJM 2011;104:505-11.

6. Braunwald E. Biomarkers in heart failure. $\mathrm{N}$ Engl J Med 2008;358:2148-59.

7. Egom EE. BNP and heart failure: preclinical and clinical trial data. J Cardiovasc Transl Res 2015;8:149-57.

8. Kakoullis L, Giannopoulou E, Papachristodoulou E, et al. The utility of brain natriuretic peptides in septic 
shock as markers for mortality and cardiac dysfunction: A systematic review. Int J Clin Pract 2019;73:e13374.

9. Parenica J, Malaska J, Jarkovsky J, et al. Soluble ST2 levels in patients with cardiogenic and septic shock are not predictors of mortality. Exp Clin Cardiol 2012;17:205-9.

10. Kandil E, Burack J, Sawas A, et al. B-type natriuretic peptide: a biomarker for the diagnosis and risk stratification of patients with septic shock. Arch Surg 2008;143:242-6.

11. Rhodes A, Evans LE, Alhazzani W, et al. Surviving sepsis campaign: international guidelines for management of sepsis and septic shock: 2016. Intensive Care Med 2017;43:304-77.

12. Dellinger RP, Levy MM, Rhodes A, et al. Surviving Sepsis Campaign: international guidelines for management of severe sepsis and septic shock, 2012. Intensive Care Med 2013;39:165-228.

13. Pirracchio R, Deye N, Lukaszewicz AC, et al. Impaired plasma B-type natriuretic peptide clearance in human septic shock. Crit Care Med 2008;36:2542-6.

14. Naqvi IH, Mahmood K, Ziaullaha S, et al. Better prognostic marker in ICU - APACHE II, SOFA or SAP II! Pak J Med Sci 2016;32:1146-51.

15. Shears M, Takaoka A, Rochwerg B, et al. Assessing frailty in the intensive care unit: a reliability and validity study. J Crit Care 2018;45:197-203.

16. Chertoff J, Chisum M, Garcia B, et al. Lactate kinetics in sepsis and septic shock: a review of the literature and rationale for further research. J Intensive Care 2015;3:39.

17. Khodashahi R, Sarjamee S. Early lactate area scores and

Cite this article as: Yang Y, Leng J, Chen R, Wang H, Hao C. Correlation between early brain natriuretic peptide level and mortality in cancer patients with septic shock. Ann Palliat Med 2021;10(4):4214-4219. doi: 10.21037/apm-20-2212 serial blood lactate levels as prognostic markers for patients with septic shock: a systematic review. Infect Dis (Lond) 2020;52:451-63.

18. Nazer LH, Rimawi D, Hawari FI. Evaluating the predictive value of lactate in patients with cancer having septic shock. J Intensive Care Med 2020;35:789-96.

19. Zhang Y, Khalid S, Jiang L. Diagnostic and predictive performance of biomarkers in patients with sepsis in an intensive care unit. J Int Med Res 2019;47:44-58.

20. Ehrman RR, Sullivan AN, Favot MJ, et al. Pathophysiology, echocardiographic evaluation, biomarker findings, and prognostic implications of septic cardiomyopathy: a review of the literature. Critical Care 2018;22:112.

21. L'Heureux M, Sternberg M, Brath L, et al. Sepsis-Induced Cardiomyopathy: a Comprehensive Review. Curr Cardiol Rep 2020;22:35.

22. Vallabhajosyula S, Pruthi S, Shah S, et al. Basic and advanced echocardiographic evaluation of myocardial dysfunction in sepsis and septic shock. Anaesth Intensive Care 2018;46:13-24.

23. Liu Z, Xing X. Research Progress of PiCCO on EGDT in Patients with Septic Shock. Advances in Clinical Medicine 2018;8:275-80.

24. Monitoring EP. Changing Characteristics of Extravascular Lung Water After Fluid Resuscitation in Septic Shock Patients by Early PiCCO Monitoring. Science 2019;7:187-92. 